\title{
Knowledge, sexual behaviours and risk perception of sexually transmitted infections among students of the polytechnic, Ibadan, Oyo state
}

\author{
Irikefe M Oharume
}

Department of Health Promotion and Education, Faculty of Public Health, University of Ibadan.

\begin{abstract}
Background: Current evidence shows that the surge of sexually transmitted infections (STIs) is of public health importance. In Nigeria, about 3 million cases of STIs are reported annually with the highest rates observed among young people.

Objective: This study was designed to investigate the knowledge, sexual behaviours and risk perception of STIs among students of the polytechnic, Ibadan.

Method: The study was a descriptive cross-sectional survey which involved the use of a four-stage sampling technique to select 401 students across the five faculties of the institution.

Results: Among the students interviewed, few (18.7\%) had good knowledge of STIs with overall mean knowledge score of 5.9 \pm 3.6. Majority (65.3\%) were sexually active in the last 12 months; while $26.7 \%$ had multiple sex partners in the last six months. Only $23.1 \%$ of single sexually active students used condom regularly. Few $(14.2 \%)$ of the students considered themselves to be at risk of contracting STIs. However, there were significant associations between knowledge and risk perception of contracting STIs; and between having multiple sex partners and the risk perception of contracting STIs.

Conclusion: These results emphasise the need to provide students with more information about STIs with the aim of positively influencing their self-perceived risk and sexual behaviour.

Keywords: Knowledge, sexual behaviours, risk perception, STIs, polytechnic, Ibadan, Oyo state.

DOI: https://dx.doi.org/10.4314/ahs.v20i1.7

Cite as: Oharume IM. Knowledge, sexual behaviours and risk perception of sexually transmitted infections among students of the polytechnic, Ibadan, Oyo state. Afri Health Sci. 2020;20(1):39-44. https:// dx.doi.org/10.4314/abs.v20i1.7
\end{abstract}

\section{Introduction}

The term sexually transmitted infection (STI) refers to an infection with any germ that can cause a sexually transmitted disease (STD) even if the infected person has no clear symptoms or symptoms at all. Sexually transmitted infections (STIs) are a major global cause of acute illness, infertility, long-term disability and death with serious medical and psychological consequences for millions of men, women and infants ${ }^{1}$. The burden of STIs is at a high worldwide in terms of their associated morbidity, mortality and socio-economic impact, with sub-Saharan Africa having a greater share of this proportion ${ }^{2,3}$.

\section{Corresponding author: \\ Irikefe M Oharume, \\ Plot 1904, Gbazango District \\ F14 Kubwa, Abuja. \\ Tel: (+234) 7065024022 \\ Email: ioharume@gmail.com}

Several studies have found varying levels of knowledge of STIs among young people who are the most vulnerable population to acquire the infections. For instance, while a study in Nigeria reported a high level (87.4\%) of knowledge of STIs among students in a tertiary institution ${ }^{4}$, the result from a study in Lao PDR, revealed a mean score of knowledge of STIs among adolescents of 3.4 out of 12 , suggesting poor knowledge $\mathrm{e}^{5}$

Unsafe sexual activities among young people which are risk factors for STIs including HIV/AIDS is on the increase, due in part to the changing social structure of young people as well as the behavioral choices that come along with this transformation ${ }^{6}$.

Perceptions of risk and their actual correlations to behaviors need to be examined to facilitate optimal prevention strategies ${ }^{7}$. While some literature suggests that individuals' knowledge of STIs including HIV/AIDS transmission have positive impact on peoples risk perception and hence the adoption of safer sexual practices ${ }^{8}$, others report that there is no association between them? 
Most studies conducted in Nigeria on knowledge of STIs ${ }^{6,10}$ based their assessment on awareness which is not a true test of STI knowledge. Therefore, one of the aims of this study was to assess knowledge of STIs using more detailed indicators such as knowledge of symptoms, types, mode of transmission and complications associated with STIs. Also, young people are known to indulge in unhealthy sexual lifestyles ${ }^{6,11,12,13}$, however, studies that explore their sexual behaviours in relation to STIs are limited in Nigeria. The data from this study will provide more insight on the Nigerian situation.

\section{Methodology}

The study was a quantitative cross-sectional descriptive survey which was carried out at the polytechnic, Ibadan, Oyo State.

The population for this study were students of the polytechnic, Ibadan main campus, admitted for the academic programmes of the institution.

The minimum sample size was determined using the formula for single proportion ${ }^{14}$ :

$$
\mathrm{n}=\frac{\mathrm{Z}^{2} \mathrm{p}(1-\mathrm{p})}{\mathrm{d}^{2}}
$$

Based on the estimated proportion of knowledge of STI Symptoms taken as $17.9 \% 20,95 \%$ confidence limit of survey and $5 \%$ precision level, the estimated minimum sample size was approximately $226(\mathrm{Z}=1.96 ; \mathrm{p}=0.17$; $\mathrm{d}=0.05)$. However, 480 students were sampled to allow for non-response and to increase the precision of the study ${ }^{4}$.

A multistage sampling technique involving four stages was used to select 480 students from the student population. All five faculties and one third of the thirty departments in the school were used for the study to ensure adequate representation.

Stage one: Proportionate sampling technique was used to determine the number of departments to be selected from each faculty. The proportions for the five faculties were; business and communication studies (3), engineering (2), environmental science (2), financila and management studies (1), science (2).

Stage two: This involved selection of the departments from each faculty. It involved simple random sampling through the use of simple ballot.
Stage three: The number of respondents selected from each department was determined by using proportionate sampling. The proportions for the departments were; accountancy (743), architecture (187), civil engineering (404), electrical engineering (617), geology (50), marketing (163), microbiology (150), music technology (281), office technology and management (480), survey and geoinfomatics (317).

Stage four: This was the final sampling stage which involved the use of systematic random sampling technique to select the required number of students from each department.

The instrument used was a self-administered semi-structured questionnaire which was designed by the researcher using information gotten from relevant literatures.

The research data was analysed with SPSS software (Version 20). Simple descriptive statistics (Frequency, Percentages and Mean) as well as Chi-square $(\chi 2)$ tests (at $\mathrm{p}=0.05$ level of significance) were used for the analyses.

\section{Results}

Out of the 480 questionnaires administered, 417 questionnaires were retrieved. Out of this number, 16 questionnaires were rejected due to poor filling. The data analysis was done with 401 questionnaires.

Thesocio demographic characteristics of the respondents showed that there were more males $(61.8 \%)$ than females $(38.2 \%)$. The age of the respondents ranged from 15 to 45 years with a mean age of $22 \pm 3.4$. Almost all (95\%) the respondents were single.

All the 14 variables in the knowledge section of the research questionnaire were scored and a twenty point knowledge scale was generated. Overall knowledge of STIs was therefore assessed using the 14 -item 20 point scale; scores less than or equal to 9 were categorized as poor, while scores greater than or equal to 10 were categorized as good. The results showed that only a few $(18.7 \%)$ of the respondents had good knowledge of STIs.

The result of respondents' sexual behavior indicated that most $(65.3 \%)$ were sexually active within the past 12 months, $40.9 \%$ of the sexually active respondents had multiple sex partners in the past 6 months representing $26.7 \%$ of the entire respondents. Majority $(76.9 \%)$ of 
the sexually active single respondents do not use condom regularly

Majority (74.6\%) of the respondents were not afraid of contracting STIs, similarly majority $(68.6 \%)$ of them do not consider themselves to be at risk of contracting an STI due to their current sexual behavior.

Table 1. Cross tabulation showing the relationship between Knowledge and the practice of having multiple sex partners

\begin{tabular}{|lc|c|c|c|}
\hline \multirow{2}{*}{} & & \multicolumn{2}{|c|}{ Multiple Sex partners } & \multirow{2}{*}{ Total } \\
\cline { 3 - 4 } & Poor & $85(21.2 \%)$ & No & \\
\hline $\begin{array}{l}\text { Knowledge } \\
\text { category }\end{array}$ & Good & $22(5.5 \%)$ & $50(12.5 \%)$ & $72(18.0 \%)$ \\
& & $107(26.7 \%)$ & $294(73.3 \%)$ & $401(100.0 \%)$ \\
& Total & & & \\
& & & & \\
& & & & \\
&
\end{tabular}

Table 2. Cross tabulations of key variables showing level of association

\begin{tabular}{|l|l|l|l|l|}
\hline SN & Cross Tabulations & $\mathbf{X}^{2}$ & $\mathbf{p ~ v a l u e}$ & Decision \\
\hline 1 & Gender and knowledge of STIs & 0.016 & 0.900 & No association \\
\hline 2 & $\begin{array}{l}\text { Knowledge and having multiple sex } \\
\text { partners }\end{array}$ & 0.462 & 0.248 & No association \\
\hline 3 & $\begin{array}{l}\text { Knowledge of STIs and frequency } \\
\text { condom use }\end{array}$ & 0.058 & 0.971 & No association \\
\hline 4 & $\begin{array}{l}\text { Knowledge of STIs and risk } \\
\text { perception of contracting STIs }\end{array}$ & 6.786 & 0.034 & Significant association \\
\hline 5 & $\begin{array}{l}\text { Having multiple sex partners and } \\
\text { risk perception of contracting STIs }\end{array}$ & 21.638 & 0.00 & Significant association \\
\hline 6 & Frequency of condom use and risk & 7.286 & 0.295 & No association \\
\hline
\end{tabular}

\section{Discussion}

\section{Socio-demographic characteristics}

The socio demographic characteristics of the students presented indicate that there were more males than females. The age of the respondents ranged from 15 to 45 years with a mean age of $22 \pm 3.4$. Similar findings were reported in previous studies among students of tertiary institutions ${ }^{6,15}$.

\section{Knowledge of STIs}

Previous studies in Nigeria have reported quite a high level of knowledge of STIs ${ }^{4,10}$, however, the findings in this study is quite at variance, as the mean score of overall knowledge of STIs was 5.9 out of 20, suggesting poor knowledge. A notable explanation for the remarkable difference in knowledge level between this study and others is that, while others assessed knowledge based on aware- 
ness of the types of STIs, this study based its assessment on types, symptoms, treatment and complications associated with STIs. The fact that this study was conducted in a tertiary institution where the respondents are expected to be more knowledgeable and aware of important reproductive health issues makes the case even more worrisome.

\section{Sexual behaviour of respondents}

The result of respondents' sexual behaviour agrees with findings of previous studies that have reported a high rate of sexual activeness among young people $\mathrm{e}^{12,13,16,17}$. The level of sexual activeness here may be due to the tendency for young people to have inordinate sexual drive that usually overcomes moral values especially when they are given the luxury to control their daily lives.

The prevalence of multiple sex partners recorded in this study is low when compared with that of a previous study where $62.3 \%$ had more than one sex partner in the last two months that preceded the study ${ }^{18}$. The findings in this study confirm the claim that sex is a phenomenon currently ravaging higher institutions in Nigeria as a lot of students are engaged in premarital and heterosexual relationships on campus due to the freedom campus life provides $^{6,12,17}$.

The distribution of sexually active single respondents based on the consistency of condom use conforms to a study conducted in Kano which also reported low condom use among respondents ${ }^{19}$. The low percentage of people using condoms, suggests that students may have unrealistic ideals about their ability to develop disease.

\section{Risk perception of STIs}

The study revealed a tendency for the respondents to underreport their risk of contracting STIs as majority of them reported that they did not think that their current sexual behaviour puts them at risk of infection with STIs. This is despite the prevalence of high risky sexual behaviours among them. This finding was consistent with previous studies carried out elsewhere ${ }^{20,21}$. This could be a reflection of their low level of knowledge about STIs because misconceptions and erroneous views about STI transmission may influence decisions and also make people interpret the actual odds of getting an infection wrongly.

\section{Gender and knowledge of STIs}

The study found that males had better knowledge of STIs than female, however the observed difference was not statistically significant. This contrasts another study conducted among students in an urban United States District which revealed a significant association between knowledge of STIs and gender ${ }^{22}$.

\section{Knowledge and sexual behaviours}

Analysis of the relationship between knowledge of STIs and the practice of having multiple sex partners is presented in table 1. The observed relationship was not statistically significant (Table 2). Similarly, analysis of respondents' knowledge of STIs and condom use showed that there was no statistically significant association between both variables (Table 2). Both analyses imply that knowledge had no influence on both sexual behaviours among the respondents. Similar findings were reported by other authors ${ }^{11,12}$ which reinforces the assertion that knowledge does not necessarily transcend into adoption of good health practices especially among young persons. In this study, knowledge in itself may not have been sufficient in influencing the sexual behaviours of the respondents due to other factors such as peer pressure and transactional sex which are common among young people.

\section{Knowledge of STIs and risk perception}

The study found knowledge to be associated with risk perception of STIs (Table 2) which is an indication that the respondents may have applied their knowledge of STIs in assessing their risk. Respondents who had good knowledge of STIs might have felt more at risk because they knew that they might get infected. This result was similar to the findings of previous studies ${ }^{5,20}$ which reported a positive relationship between risk perception and knowledge of STIs/HIV. However, a previous study found that having more knowledge about STIS did not significantly influence the risk perception STIs 9

\section{Multiple sex partners and risk perception of STIs}

The study findings showed that respondents' risk perception of contracting STIs was influenced by the practice of having multiple sex partners. A previous study also found that having multiple sex partners influences the perceived risk of STIs among young people ${ }^{5}$ This fur- 
ther emphasises the tendency of young people to adopt risky lifestyles despite their awareness of the dangers that accompany such lifestyles.

\section{Recommendations}

STI education materials should have contents that can provide sufficient information to target audiences. The establishment of youth driven clubs for reproductive health purposes will also go a long way in providing adequate STI information to young people. Also, the fact that the study reported a high rate of irregular and non-condom use among students calls for more attention in the area of promoting condom use among students as well as encouraging abstinence in the prevention of STIs.

\section{Acknowledgement}

The author appreciates the management and students of the polytechnic, Ibadan, for providing an enabling environment for the conduct of the research. Special recognition also goes to the Late Professor JD Adeniyi, for his excellent supervision.

\section{Competing interests}

The author has no competing interest to declare.

\section{References}

1. WHO. Global Incidence and Prevalence of Selected Curable Sexually Tranmitted Infections - 2008. Geneva: WHO Press, 2012.

2. Dyck VE, Meheus AZ, Piot P. Laboratory Diagnosis of Sexually Transmitted Diseases. Geneva: WHO Press, 1999.

3. Usanga VU, Abia-Bassey PC, Inyang-etoh SU, Ani F, Archibong E. Prevalence of Sexually Transmitted Diseases in Pregnant and Non-Pregnant Women in Calabar, Cross Rivers State, Nigeria. The International Journal of Gynecology and Obstetrics 2010; 14(2): 56-59

4. Makwe E, Ahmad HA. Attitude, Sexual Behaviour and Risk Perception to Sexually Transmitted Infections Including HIV/AIDS among Students of University of Abuja, Nigeria. British Journal of Education, Society \& Behavioural Science 2014; 4(3): 350-361.

5. Sychareun V, Thomsen S, Chaleunvong K, Faxelid E. Risk Perceptions of STIs/HIV and Sexual Risk Behaviours among Sexually Experienced Adolescents in the Northern part of Lao PDR. BMC Public Health 2013; 1126(13).

6. Imaledo JA, Peter-Kio OB, Asuquo E O. Pattern of risky sexual behavior and associated factors among undergraduate students of the University of Port Harcourt, Rivers State, Nigeria. The Pan African Medical Journal 2012; 12:97.

7. Zinn JO. Heading into the Unknown: Everyday Strategies for Managing Risk and Uncertainty. Health, Risk \& Society 2008; 10(5): 439-450.

8. Cates W. Teenagers and Sexual Risk taking: The best and worst of times. Journal of Adolescent Health 1991; 12: 84-94.

9. Stringer EM, Sinkala M, Kumwenda R, Chapman VV, Mwale A, Vermund SH et al. Personal risk perception, HIV knowledge and risk avoidance behavior, and their relationships to actual HIV serostatus in an urban African obstetric population. Journal of Acquired Immune Deficiency Syndrome 2004; 35(1):60-66.

10. Adegun PT, Solomon OA, Adegoke SA, Ade-Ojo IP \& Fape MO. Knowledge of Sexually Transmitted Infections among Patients attending Outpatient Clinics at University Teaching Hospital, Ado-Ekiti, Nigeria. Journal of Public Health and Epidemiology 2013; 5(March): 110-114. 11. Temin MJ, Okonofua FE, Omorodion FO, Renne EP, Coplan P, Heggenhougen HK, Kaufman J. (1999). Perceptions of Sexual Behavior and Knowledge About Sexually Transmitted Diseases among Adolescents in Benin City, Nigeria. International Family Planning Perspectives, 25(4), 186-190 \& 195.

12. Anwar M, Sulaiman SA, Ahmadi K, Khan TM. Awareness of School Students on Sexually Transmitted Infections (STIs) and their Sexual Behavior: a Cross-sectional Study conducted in Pulau Pinang, Malaysia. BMC Public Health 2010; 10(1): 47.

13. Cherie A, Berhane Y. Knowledge of Sexually Transmitted Infections and Barriers to Seeking Health Services among High School Adolescents in Addis Ababa, Ethiopia. Journal of AIDS and Clinical Research 2012; 3(5).

14. Bamidele AF. Basic Statistics. 2nd ed. Lagos: Ideal Quality Press, 2009; Pp81.

15. Kadiri KK, Ahmad MK \& Mustaffa CS. Knowledge and Treatment Seeking Behaviour of University of Ilorin Students in Kwara State, Nigeria. New Media and Mass Communication 2014; 27: 41-47.

16. National Population Commission (NPC) [Nigeria] and ICF International. Nigeria Demographic andHealth Survey 2013. Abuja, Nigeria and Rockville, Maryland, USA: NPC and ICF International 2014.

17. Shiferaw Y, Alemu A, Girma A, Getahun A, Kassa A, Gashaw A, Gelaw B. (2011). Assessment of knowledge, 
Attitude and Risk Behaviors towards HIV/AIDS and other Sexual Transmitted Infection among Preparatory Students of Gondar Town, North West Ethiopia. Biomed Central Journal , 4(1), 505.

18. Fawole AO, Ogunkan DV, Adegoke GS. Sexual Behaviour and Perception of HIV/AIDS in Nigerian Tertiary Institutions: University of Ilorin, a Case Study. Global Journal of Human Social Science 2011; 11: (1):1.

19. Kabir M, Iliyasu Z, Abubakar IS, Kabir AS. Sexual Behaviour among Students in Tertiary Institutions in kano, Northern Nigeria. Journal of Community Medicine and Primary Health Care 2004; 16(2):17-22.
20. Prata N, Morris L, Mazive E, Vahidnia F, Stehr M. Relationship between HIV Risk Perception and Condom use: Evidence from a Population-based Survey in Mozambique. Int Fam Plann Perspect 2006; 32(4):192-200.

21. Adedimeji AA, Omololu FO, Odutolu. HIV Risk Perception and Constraints to Protective Behaviour among Young Slum Dwellers in Ibadan, Nigeria. Journal of Health, Pори \& Nutri 2007; 25(2):146-157.

22. Nsuami MJ, Sanders LS, Taylor SN. Knowledge of Sexually Transmitted Infections among High School Students. American Journal of Health Education 2010; 41(4): 206-217. 